\title{
Development and Validation of a Questionnaire to Assess Creative Potential Traits
}

\author{
Julio C. Penagos-Corzo* and Axel Saucedo \\ Department of Psychology, Universidad de las Américas Puebla, Cholula, Mexico
}

The aim of the study was to develop an inventory to assess traits of creative potential and to analyze its psychometric properties. Three dimensions that could be associated with creative potential were proposed: willingness to transgress, willingness to take on challenges, and willingness to explore. For this purpose 551 participants were chosen to respond to an inventory composed of 12 items: Traits of Creative Potential Questionnaire, (TCPQ-12) and other tests to determine concurrent validity. The correlations between these instruments were significant. In addition, the instrument showed adequate internal consistency $(\Omega=0.813)$ and the exploratory factor analysis

OPEN ACCESS

Edited by:

João P. Marôco,

University Institute of Psychological,

Social and Life Sciences (ISPA),

Portugal

Reviewed by:

Patrícia Silva Lúcio,

State University of Londrina, Brazil Antonio Hernández-Mendo, University of Malaga, Spain

${ }^{*}$ Correspondence: Julio C. Penagos-Corzo julioc.penagos@udlap.mx

Specialty section:

This article was submitted to Quantitative Psychology and Measurement a section of the journal Frontiers in Psychology

Received: 10 August 2021 Accepted: 07 October 2021 Published: 04 November 2021

Citation:

Penagos-Corzo JC and Saucedo A (2021) Development and Validation of a Questionnaire to Assess Creative Potential Traits.

Front. Psychol. 12:756079. doi: 10.3389/fpsyg.2021.756079 yielded salient factors coincident with the proposed dimensions. The confirmatory factor analysis indicated an optimal fit $(\mathrm{CFI}=0.984, \mathrm{TLI}=0.979, \mathrm{GFI}=0.963, \mathrm{RMSEA}=0.035)$. with composite reliability (CR) values $>0.70$ in two factors and in one was slightly lower $(\mathrm{CR}=0.684)$. The average variance extracted (AVE) was $>0.5$ in two factors and in one $<0.5$. The study data allow to highlight that the instrument presented here is a concise instrument with adequate psychometric properties.

Keywords: creativity, risk-taking, rule-breaking, willingness to explore, transgression, personality

\section{INTRODUCTION}

Creativity can be identified as a capacity that allows generating products that have originality and value (Runco and Jaeger, 2012; Diedrich et al., 2015; Corazza, 2016; Romo, 2019). There is evidence indicating that this capacity has biological (Sawyer, 2011; Penagos-Corzo, 2018; Deshayes et al., 2021), motivational (de Jesus et al., 2013; Liu et al., 2016; Taylor and Kaufman, 2021), affective (Baas et al., 2008, 2011; Mielniczuk and Laguna, 2020) and cognitive components (Benedek et al., 2014; Sampedro and Peña, 2019; Milicevic et al., 2020) that can enhance it. In addition to these components, some personality characteristics or traits have been associated with creativity practically since the contemporary beginning of its study (Guilford, 1950; MacKinnon, 1963) and in influential later works (Eysenck, 1993, 1994; MacKinnon, 1975/2017). More recent studies continue to yield evidence for the link between personality traits and creativity (George and Zhou, 2001; Furnham et al., 2008; Prabhu et al., 2008; Batey et al., 2010; Guo et al., 2021; Zhou, 2021). In fact, it is probably the individual's unique personality that enables or hinders the development of creative ideas (Mumford and Gustafson, 1988). However, personality traits are relatively little addressed for the development of instruments related to the assessment of creative potential.

Openness to experience is a personality trait that can predict $10-50 \%$ of creativity (Sawyer, 2012). Its link to creativity is independent of the type of measure or domain of creativity (Hornberg and Reiter-Palmon, 2017). Some relevant characteristics of this trait are: preference for variety, 
challenge to authority, and curiosity (McCrae and Costa, 2008). The latter is not only related to creativity (Chang and Shih, 2019; Tsai and Zheng, 2021), but such relationship has a causal sense (Hagtvedt et al., 2019). In this sense, evidence indicates that curiosity positively predicts information seeking and negatively predicts intolerance of uncertainty (Jach and Smillie, 2021). This supports operational definitions of curiosity, which describe it as a preference for uncertainty (Jirout and Klahr, 2012). It can also be understood as a desire to discover information and experiences while motivating behavior (Hamilton, 2019). In fact it is an essential part of intrinsic motivation and can be considered as an innate need to explore (Grigorescu, 2020). Empirical data suggest that exploration is a vital component of creativity (Evans et al., 2021), as is intrinsic motivation (Amabile and Pratt, 2016). Data indicate that this is transmitted toward creativity in the form of an increased willingness and desire to take on challenges or risks (Dewett, 2007).

Conformity to social norms seems to be related to low creativity (Mu et al., 2015), and conversely nonconformity may be a predictive component of higher creativity (Fürst et al., 2016), especially impulsive nonconformity (Schuldberg, 1990). This is congruent with studies indicating that impulsivity and risk-taking are related to creativity (Xia et al., 2017). Higher risk takers score high on flexibility and originality (Glover and Sautter, 1977), which are characteristic variables of creativity. Consistent with the above, it has been suggested that people with high creativity possibly have more propensity toward risk (Sternberg and Lubart, 2002). In this sense, experimental studies indicate that environments that encourage risky decision making, as compared to environments that encourage safetybased decisions, produce more creative performances (Friedman and Förster, 2001). Indeed recreational and primarily social risk taking is linked to creative personality (Tyagi et al., 2017). When this risk-taking is assessed, what is observed are behaviors that generally transgress or violate norms or expectations (Highhouse et al., 2017). In children, transgressive play has been found to be related to better creative performances (Møller, 2015).

It is important to note that creativity is not something that happens in isolation. It is linked to the product and its social recognition (Romo, 2019). The social environment -or the field- somehow qualifies what is or is not creative (Csikszentmihalyi, 2013). However, the creative person is able to recognize opportunities in the environment and associated success (Chang and Chen, 2020). Given this interaction with the social environment, social skills are relevant so that the person who performs a creative act is not constrained by the impositions of the environment. In this sense, it has been observed that social skills are related to creativity (Lee et al., 2002; Hahn et al., 2011; Aydintan et al., 2014). Another variable that may be relevant in overcoming the pressures of the social environment is a willingness to challenge. Evidence indicates challenge seeking results in a good predictor of creative expression (Epstein and Phan, 2012).

Despite the above evidence regarding personality and creativity, there seem to be no quick and concise measures that assess traits predictive of creative potential. Some measures such as the Creative Personality Scale (CPS) (Gough, 1979) come close and even more recent versions can be found (FreibergHoffmann et al., 2019). The CPS consists of a list of 30 adjectives. Eighteen are indicative of creativity and 12 are contraindicative. Examinees must select on a dichotomous scale $(+$ or -$)$ whether the item describes them. The score is obtained by adding the selected indicative adjectives and subtracting the chosen contraindicative adjectives. The CPS in its first version (Gough and Heilbrun, 1965/1983) obtained an internal consistency of 0.63. It was subsequently tested in four samples (Gough, 1979). The internal consistency of the instrument in these samples ranged from an alpha of 0.73 to 0.81 and convergent validity indices ranged from 0.14 to 0.40 . More recent work reports an alpha of 0.85 , but with a weak convergent validity correlation of 0.20 and a unifactorial structure (Freiberg-Hoffmann et al., 2019). Other studies indicate alphas between 0.59 and 0.64 and a culture-dependent multifactor structure (Luescher et al., 2019). In previous paragraphs it was indicated that there was evidence that personality variables linked to exploration (Evans et al., 2021), transgression (Møller, 2015; Fürst et al., 2016) and risk-taking or challenge (Dewett, 2007; Epstein and Phan, 2012) predict creative performances. Therefore the aim of the present study is to evaluate the psychometric properties of a trait inventory of creative potential based on these three dimensions.

\section{MATERIALS AND METHODS}

\section{Participants}

The sample consisted of 551 Mexican participants, of whom 356 were women and 195 men. The mean age was 34.3 years $(\mathrm{SD}=16.2)$. The schooling of the women was as follows: $51.97 \%$ were college students, with an average age of 20.6 years $(S D=5.6$ ), $40.45 \%$ were graduates and/or postgraduate students, with an average age of 46.2 years $(S D=11.1)$ and finally $7.58 \%$ had a high school diploma, with an average age of 47.5 years $(\mathrm{SD}=13.7)$. The schooling of the males was as follows: $40.51 \%$ had undergraduate studies, with an average age of 21.2 years ( $\mathrm{SD}=5.5), 53.85 \%$ were graduates and/or postgraduate students, with an average age of 47.9 years $(S D=12.1)$ and finally $5.64 \%$ had only studied up to high school, with an average age of 47.5 years $(S D=17.3)$. The sample was split into two, one for exploratory factor analysis (subsample A [SSA]) and one for confirmatory factor analysis (subsample B [SSB]). The SSA $(N=276)$ consisted of 162 women and 114 men. The SSB $(N=275)$ consisted of 194 females and 81 males. All subjects gave written informed consent in accordance with the Declaration of Helsinki (World Medical Association, 2013). This study was reviewed and approved by the Ethics Committee of the Universidad de las Américas Puebla.

Undergraduate students were invited to participate through an invitation made in various classes and also through the official social networks of the university's psychology department. An online invitation was also made to the adult public, through a mailing list of professionals. Not having completed high school and being under 18 years of age were considered as exclusion criteria. The questionnaires of participants who responded to all the instruments in a period of less than four minutes were also excluded, as this was considered an unreasoned response strategy 
and probably random, due to the impossibility of having read all the items, evaluated and selected the answer in this time. The application also incorporated four items to evaluate social desirability and random responses. If participants answered positively to one of these items, their questionnaires were not taken into account. An example of an item to assess whether the person was responding randomly was: "I forget how to spell my name." An example to assess social desirability is the item: "I have never told a single lie in my life." 22 participants were discarded because they met any of the exclusion criteria. The inclusion criterion was that they were university students or working adults.

\section{Instruments}

Traits of Creative Potential Questionnaire (TCPQ-12). This questionnaire was developed in the present study and has twelve items created based on three dimensions: Exploration, Transgression, Challenge. The response options are by means of a seven-point scale, where $1=$ does not look like me, 7 = looks like me.

Big 5: Openness to experience factor (Benet-Martínez and John, 1998). This instrument assesses five personality factors. The validation for Mexican population (Zamorano et al., 2014) was used, in which an adequate consistency was reported $(\alpha=0.72)$. Only the factor of openness to experience was applied, consisting of 10 items ( $\alpha=0.77$ ).

Domain Specific Risk Taking (Dospert): Social and Recreational Factors (Blais and Weber, 2006). The 30-item Dospert scale ( $\alpha=0.71$ to 0.86 ) assesses domain specific risk taking. The subdomain of risk taking in social (6 items) and recreational (6 items) areas was used. This test is answered by choosing a number between 1 (Extremely unlikely) and 7 (Extremely likely) according to the probability that a behavior will be committed. Higher scores indicate greater risk taking.

Political Skill Inventory (PSI): Social Astuteness Factor (Ferris et al., 2005). This 18 -item instrument $(\alpha=0.89)$ assesses political skill. The social astuteness factor (5 items) was taken, which assesses the ability to observe and evaluate others, as well as adjust behavior in a wide range of social contexts $(\alpha=0.80)$. This instrument is answered from 1 to 7 where 1 is "strongly disagree" and 7 is "strongly agree." Higher scores indicate greater social astuteness.

The Cognitive Flexibility Inventory (CFI) (Dennis and Vander Wal, 2010). The Cognitive Flexibility Inventory contains 20 items $(\alpha=0.90)$ measures an individual's ability to change cognitive sets and adapt to changing stimuli in the environment. It is composed of two subscales: a) Alternatives (13 items) $(\alpha=0.91)$ and b) Control ( 7 items) $(\alpha=0.86)$. This inventory is answered by rating from 1 to 7 scores, where 1 is "I strongly disagree" and 7 is "I strongly agree." Higher scores represent greater flexibility.

Work Preferences Inventory (WPI) (Amabile et al., 1994). This instrument evaluates intrinsic and extrinsic motivation. A version that was validated in a Mexican sample was used (Penagos-Corzo et al., 2017). Only the intrinsic motivation factor $(\alpha=0.82)$ was applied, divided into two subscales: (a) Joy subscale with 7 items (WPI-G) $(\alpha=0.65)$ and (b) Challenge subscale with 5 items (WPI-D) $(\alpha=0.65)$. This instrument has 4 response options: from "Never or almost never true in my case," to "Always or almost always true in my case." Higher scores represent an individual with high intrinsic motivation.

Kaufman Domains Of Creativity Scale (K-DOCS) (Kaufman, 2012). The K-DOCS is an inventory that measures creativity from self-assessments on reported behaviors, focusing on 5 specific domains: Self/Everyday $(\alpha=0.86)$, Scholarly $(\alpha=0.86)$, Performance $(\alpha=0.87)$, Mechanical/scientific $(\alpha=0.86)$, and Artistic $(\alpha=0.83)$. Response options range from 1 to 5 where 1 is "much less creative" and 5 is "much more creative." Higher scores indicate greater creativity.

\section{Procedure}

The psychometric study carried out started with the initial development of items, which were evaluated by a group of experts, then tested in a pilot study and finally the resulting items were applied to the general sample for reliability and validity analyses. The graphical abstract shows this process (Figure 1).

\section{Item Development}

For the generation of the items, the recommendations indicated by Boateng et al. (2018) were taken into account, placing special emphasis on the deductive or logical partitioning method. This is done through literature review and evaluation of existing indicators of the domain to be measured. The items were developed in consideration of the findings of personality variables that have effects on creativity: Willingness to explore (Evans et al., 2021), transgressing norms or rules (Møller, 2015; Fürst et al., 2016), Willingness to challenge (Dewett, 2007; Epstein and Phan, 2012). Based on the above, the authors developed and determined 21 items that were intended to measure the three dimensions of the instrument. Seven items were created for each dimension. These items were the ones that the experts evaluated to determine the content validity.

\section{Content Validity}

For content validity, these items were given to six creativity experts. All experts taught university courses related to the research topic of the present study and/or had publications on the topic. These experts were asked to evaluate the importance of the items using a three-level criterion: (a) the item is essential, (b) the item is useful but not essential, and (c) the item is not essential. To determine the items with content validity, Lawshe's (1975) content validity ratio (CVR) formula was applied, which states that $C V R=\frac{n e-\frac{N}{2}}{\frac{N}{2}}$, where ne $=$ number of experts who evaluated the item as essential and $N=$ total number of experts. The selection of the items was made based on the criteria of TristainLópez (2008): those items whose formula score was greater than 0.58 were eligible. This analysis resulted in 18 items.

\section{Pilot Study}

The 18 items were tested on a pilot sample of 108 participants. The sample was selected through an invitation made in social media of the Psychology Department of the University and in professional social networks. 59 females with a mean age of 34.05 $(\mathrm{SD}=12.24)$ and 49 males with a mean age of 31.57 (13.43), made up this sample. $74.58 \%$ of the females were graduate 


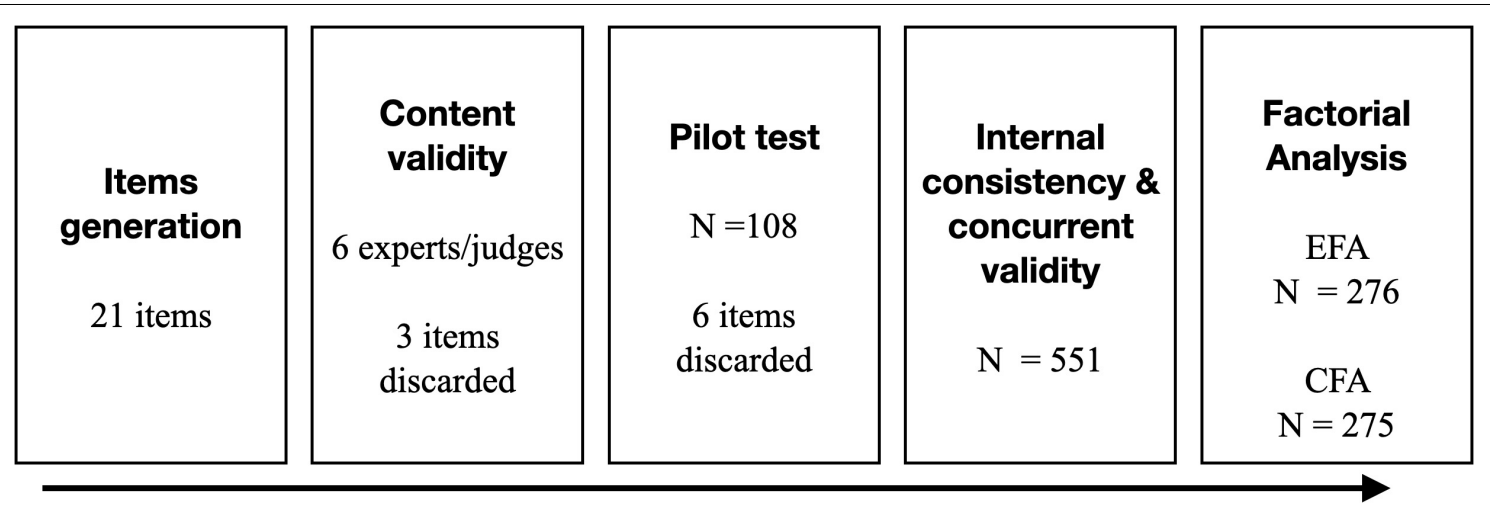

FIGURE 1 | Steps from item generation to analysis to factor analysis.

or postgraduate students, while the remaining percentage were undergraduate students. $57.14 \%$ of the males were graduate or postgraduate students, while undergraduate students made up the remaining percentage. This sample was divided into two groups to test the discrimination capability of the items: One with the $27 \%$ of participants who obtained the highest scores and another with the $27 \%$ of participants who obtained the lowest scores. With these two groups, the discrimination capability of the items was analyzed through a t-test, comparing the high vs. low group in each item (Penagos-Corzo et al., 2019). Four items that did not have significant differences at a confidence level of 0.01 were discarded. Two additional items were eliminated because they were considered clearly repetitive and a correlation analysis confirmed this (0.971-0.979).

\section{Application of Instruments for Reliability and Validity Analysis}

After this analysis, the TCPQ was administered online, along with the other instruments, to the sample of 551 participants. The other instruments were selected to assess concurrent validity. Positive relationships were hypothesized between each of the scales and the salient factors of the TCPQ. Specifically, K-Docs was expected to have the highest correlations with the instrument under development. If the transgression scale was confirmed, it was expected to correlate with DOSPERT and WPI. On the other hand, if the Exploration scale were confirmed, the highest correlations would be expected with the Openness factor of the BigFive, with the intrinsic motivation subscales of the WPI, as well as with the CFI, specifically with the alternatives subscale. Whereas for the possible Challenge dimension, correlations were expected with Social Astuteness, the intrinsic motivation subscales of the WPI and the Openness factor of the BigFive.

\section{Statistical Analysis}

Statistical analyses were performed in SPSS 24, AMOS 24 and Jamovi 2.0. An exploratory factor analysis (EFA) of the scale was performed, using principal axis factoring and promax rotation due to the conceptual consideration that the underlying factors may be correlated. Confirmatory factor analysis was assessed with the comparative fit index (CFI) the Tucker-Lewis index (TLI) and with the root mean square error of approximation (RMSEA). There is general agreement to use cut-off points of 0.95 for the CFI and TLI fit indices to consider an optimal fit, as well as values lower than 0.06 for the RMSEA (Hu and Bentler, 1999; Barrett, 2007). However, it has been suggested that $>0.97$ for CFI and TLI, as well as $<0.05$ for RMSEA are more advisable (Schermelleh-Engel et al., 2003), so the present study will use this recommendation. For GFI, a cut-off point $>0.95$ will be used, for AGFI $>0.90$, for PNFI $>0.60$ and for SRMR $<0.05$ which are also the recommended cut-off point of Schermelleh-Engel et al. (2003). For PCFI, the cut-off point $>0.6$ will be used (Marsh and Grayson, 1995). Internal consistency was evaluated using McDonald's omega. Finally, correlations between instruments and temporal stability were determined by Pearson correlations.

\section{RESULTS}

\section{Exploratory Factor Analysis}

The exploratory factor analysis with the SSA sample indicated a KMO of 0.823 , and Bartlett's test of sphericity was significant $(\mathrm{X} 266=1062.086, p<0.001)$, indicating that it was pertinent to perform the factor analysis. The extraction criterion was an eigenvalue $>1.0$ (Kaiser, 1960). In addition, a parallel analysis was performed (Horn, 1965). The AFE yielded a three-factor structure (Table 1), both with the Kaiser criteria (eigenvalue $>1.0$ ) and with the parallel analysis (Figure 2). The first factor yielded an eigenvalue of 3.825 and explained $31.88 \%$ of the total variance, while the second factor had an eigenvalue of 2.315 and explained $19.29 \%$ of the total variance, and the third factor had an eigenvalue of 1.180 and explained $9.83 \%$ of the total variance. The three factors explained $61 \%$ of the total variance.

\section{Confirmatory Factor Analysis}

A confirmatory factor analysis was performed on the SSB sample using the maximum likelihood estimation method. The model fit indices suggested an adequate fit $\chi^{2}(49)=65.02, p=0.062$ $\left(\chi^{2} / \mathrm{DF}=1.327\right)$, with optimal levels $\mathrm{CFI}=0.984$, TLI $=0.979$ and RMSEA $=0.0347$ (90\% confidence interval, 0.00 Lower, 0.0554 Upper. pClose $=0.881$ ). As shown in Figure 3, two pairs of 
TABLE 1 | Factor loadings.

\begin{tabular}{|c|c|c|c|}
\hline Items & F1 & F2 & F3 \\
\hline $\begin{array}{l}\text { i07 I have developed ideas that involve violation of certain rules. (He desarrollado ideas } \\
\text { que involucran violación de ciertas normas) }\end{array}$ & 0.724 & 0.034 & -0.083 \\
\hline $\begin{array}{l}\text { i02 I think I dare more than the average person. (Creo que me atrevo más que el común } \\
\text { de las personas) }\end{array}$ & 0.037 & 0.727 & 0.001 \\
\hline $\begin{array}{l}\text { i05 I have created original and positive things that are recognized by many people. (He } \\
\text { creado cosas originales y positivas que son reconocidas por bastantes personas) }\end{array}$ & -0.018 & 0.706 & -0.090 \\
\hline $\begin{array}{l}\text { i08 In my projects I am definitely riskier than others. (En mis proyectos definitivamente } \\
\text { soy más arriesgado/a que los demás) }\end{array}$ & 0.003 & 0.673 & 0.118 \\
\hline $\begin{array}{l}\text { i06 I tend to see things from different perspectives. (Tiendo a ver las cosas desde } \\
\text { distintas perspectivas) }\end{array}$ & 0.032 & 0.022 & 0.634 \\
\hline $\begin{array}{l}\text { i09 Just for pleasure, I strive to find out how things work. (Sólo por gusto, me esfuerzo } \\
\text { en descubrir cómo funcionan las cosas) }\end{array}$ & 0.112 & 0.045 & 0.516 \\
\hline $\begin{array}{l}112 \text { Faced with a difficult choice, I follow my intuition. (Ante una elección difícil, sigo mi } \\
\text { intuición) }\end{array}$ & -0.096 & -0.014 & 0.502 \\
\hline
\end{tabular}

Salient and highest loadings per item in bold.

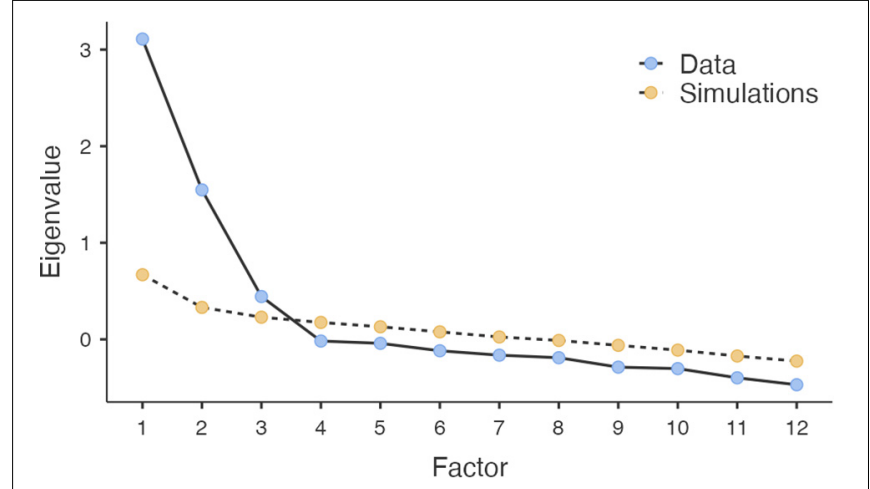

FIGURE 2 | Scree plot with data and simulations (parallel analyses).

items were co-varied, one for F1 (i01- i07) and one for F2 (i08 - i11). The goodness of fit index, parsimony and root mean squared residual also showed acceptable levels $(\mathrm{GFI}=0.963$, AGFI $=0.942$, PNFI $=0.698$, PCFI $=0.731$, SRMR $=0.0435$ ) The composite reliability data were $>0.70$ for F1 (0.811) and F2 $(0.816)$. For F3 the value was close to the cut-off point (0.684). The average variance extracted was also acceptable $(>0.5)$ for F1 (0.522) and F2 (0.531), but for F3 the value was below the cut-off point $(0.362)$. The discriminant and convergent validity analyses are presented in Table 2.

The discriminant validity analysis indicates that the AVE of F1 and F2 have higher values than the MSV. However, the AVE of F3 is lower than the MSV and also the square root of the AVE of
F3 is lower than the value of the correlations with another factor (Table 2). In addition, the AVE values obtained indicate for F1 and F2 adequate convergent validity, but F3, as already noted, has a value $<0.05$.

\section{Analysis of Invariance}

The structure of the TCPQ was analyzed between both sexes (M1). The data indicate an adequate fit $(\mathrm{CFI}=0.954, \mathrm{GFI}=0.924$, RMSEA $=0.042)$ in this analysis. Subsequently, this analysis was performed in a fully constrained model (M2). With this model the fit indices were also appropriate $(\mathrm{CFI}=0.957$, GFI $=0.920$, RMSEA $=0.039)$. The differences in chi-square between both models indicate invariance $\left(X^{2}{ }_{M 1}=145.5\right.$, $\left.d f_{M 1}=98, X^{2}{ }_{M 2}=154.8, d f_{M 2}=110, p=0.677\right)$.

\section{Concurrent Validity}

Each of the resulting factors and the total TCPQ were correlated with the other scales applied to the total sample $(N=551)$. As can be seen in Table 3 , in general the correlations are moderate and were significant. As expected for concurrent validity, the highest correlations are with K-Docs, BigFive openness and WPI intrinsic motivation. The predictions about the relationship between the transgression factor of the TCPQ and the DOSPERT, as well as with the challenge subscale of the WPI, are confirmed. While for the challenge factor of the TCPQ, the predictions of relationship with the social astuteness of the PSI, the intrinsic motivation subscales of the WPI and the openness factor of the BigFive are also confirmed. Similarly, the relationship of the exploration 


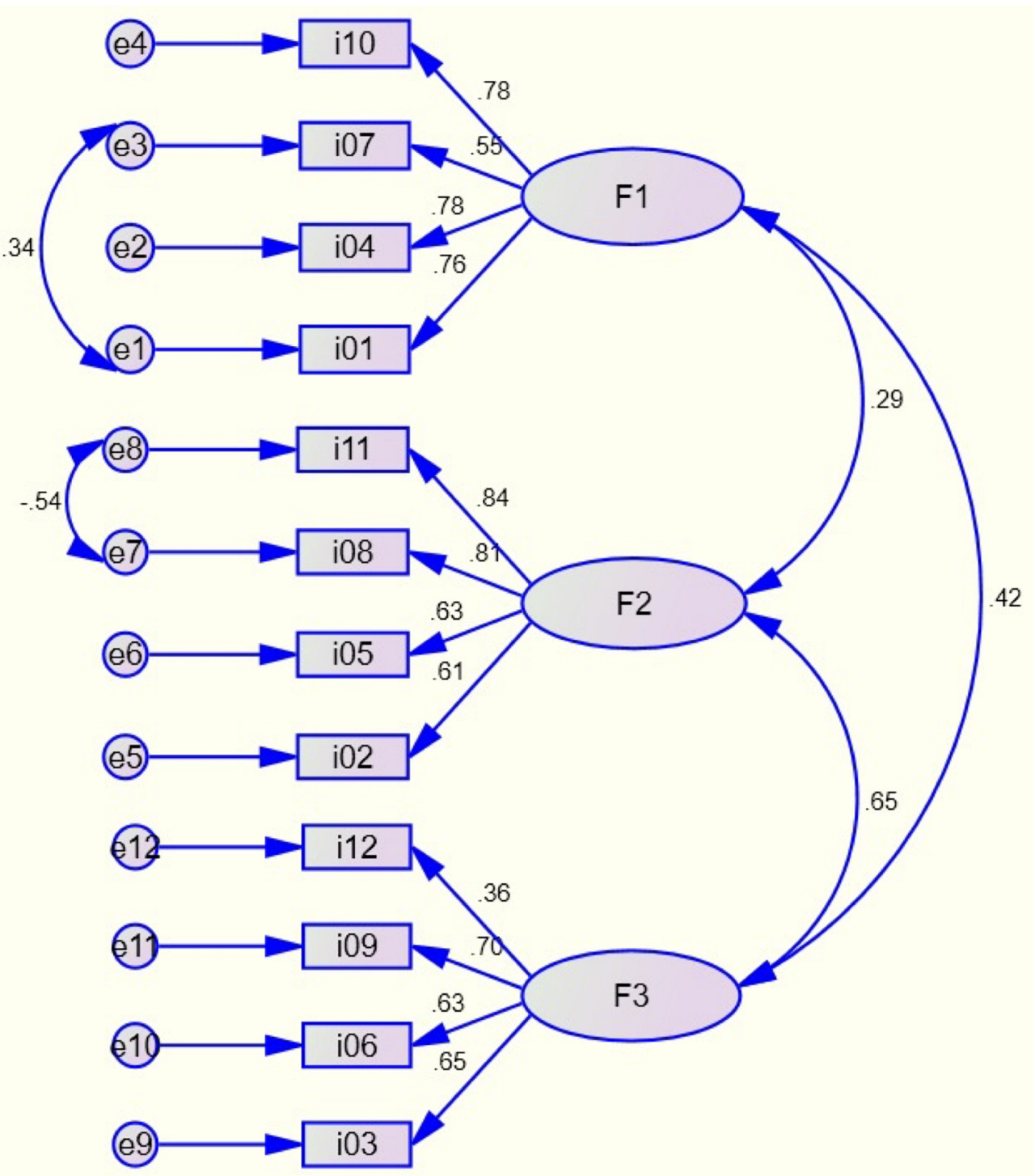

FIGURE 3 | Path analysis diagram.

TABLE 2 | Discriminant and convergent validity.

\begin{tabular}{llllll}
\hline & CR & AVE & JAVE & MSV & MaxR(H) \\
\hline F2 & 0.816 & 0.531 & 0.729 & 0.428 & 0.846 \\
F1 & 0.811 & 0.522 & 0.723 & 0.174 & 0.829 \\
F3 & 0.684 & 0.362 & 0.602 & 0.428 & 0.717 \\
\hline
\end{tabular}

CR, composite reliability; AVE, average variance extracted; $\sqrt{ }$ AVE, root square of the AVE; MSV, maximum shared variance; MaxR(H), maximum reliability.

factor of the TCPQ with the openness factor of the BigFive and with the intrinsic motivation subscales of the WPI is also confirmed.

\section{Reliability}

\section{Internal Consistency}

The results of the reliability analysis by means of the omega coefficient indicate acceptable levels for the total instrument
$(\Omega=0.813)$, as for F1 $(\Omega=0.833)$, F2 $(\Omega=0.797)$ and F3 $(\Omega=0.683)$. The internal consistency analysis was performed with the total sample $(N=551)$.

\section{Temporal Stability}

The temporal stability analysis was conducted with a combination of the participants from the original sample who agreed to answer the questionnaire again $(n=188)$ and 
TABLE 3 | Pearson's correlations amongst tests and factors.

\begin{tabular}{|c|c|c|c|c|c|c|c|c|c|c|c|c|c|c|c|c|c|}
\hline Factors/Scales & 1 & 2 & 3 & 4 & 5 & 6 & 7 & 8 & 9 & 10 & 11 & 12 & 13 & 14 & 15 & 16 & 17 \\
\hline \multicolumn{18}{|l|}{$1 \mathrm{TCPQ}-\mathrm{Tot}$} \\
\hline $2 \mathrm{TCPQ}$-Challenge & $0.717^{\star \star \star}$ & & & & & & & & & & & & & & & & \\
\hline 3 TCPQ -Exploration & $0.689^{\star \star \star}$ & $0.466^{\star \star \star}$ & & & & & & & & & & & & & & & \\
\hline 4 TCPQ -Transgression & $0.72^{\star \star \star}$ & $0.175^{\star \star \star}$ & $0.243^{\star \star \star}$ & & & & & & & & & & & & & & \\
\hline $5 \mathrm{~K}$-DOCS-Tot & $0.555^{\star \star \star}$ & $0.506^{\star \star \star}$ & $0.486^{\star \star \star}$ & $0.256^{\star \star \star}$ & & & & & & & & & & & & & \\
\hline 6 K-Docs-Self/Everyday & $0.477^{\star \star \star}$ & $0.504^{\star \star \star}$ & $0.486^{* \star *}$ & $0.134^{* *}$ & $0.637^{\star \star \star}$ & & & & & & & & & & & & \\
\hline 7 K-Docs-Scholarly & $0.524^{\star \star \star}$ & $0.509^{\star \star \star}$ & $0.444^{* \star *}$ & $0.233^{\star \star \star}$ & $0.746^{\star \star \star}$ & $0.563^{\star \star \star}$ & & & & & & & & & & & \\
\hline 8 K-Docs-Performance & $0.311^{\star \star \star}$ & $0.268^{\star \star \star}$ & $0.227^{\star \star \star}$ & $0.181^{\star \star \star}$ & $0.772^{\star \star \star}$ & $0.332^{\star \star \star}$ & $0.439^{\star \star \star}$ & & & & & & & & & & \\
\hline $\begin{array}{l}9 \text { K-Docs- } \\
\text { Mechanical/Scientific }\end{array}$ & $0.402^{\star \star \star}$ & $0.314^{\star \star \star}$ & $0.335^{\star \star \star}$ & $0.237^{\star \star \star}$ & $0.689^{\star \star \star}$ & $0.261^{\star \star \star}$ & $0.392^{\star \star \star}$ & $0.397^{\star \star \star}$ & & & & & & & & & \\
\hline 10 K-Docs-Artistic & $0.385^{\star \star \star}$ & $0.341^{\star \star \star}$ & $0.371^{\star \star \star}$ & $0.158^{\star \star \star}$ & $0.821^{\star \star \star}$ & $0.455^{\star \star \star}$ & $0.508^{\star \star \star}$ & $0.609^{\star \star \star}$ & $0.479^{\star \star \star}$ & & & & & & & & \\
\hline $11 \mathrm{CFl}$ : Alternatives & $0.336^{\star \star \star}$ & $0.376^{\star \star \star}$ & $0.426^{\star \star \star}$ & 0.024 & $0.425^{\star \star \star}$ & $0.556^{\star \star \star}$ & $0.447^{\star \star \star}$ & $0.235^{\star \star \star}$ & $0.199^{\star \star *}$ & $0.301^{\star * \star}$ & & & & & & & \\
\hline 12 CFI: Control & -0.045 & $-0.16^{\star \star \star}$ & -0.02 & $0.085^{\star}$ & -0.06 & $-0.15^{\star \star \star}$ & -0.03 & 0.025 & $-0.11^{\star \star}$ & -0.01 & $-0.18^{\star \star \star}$ & & & & & & \\
\hline 13 WPI: Challenge & $0.515^{\star \star \star}$ & $0.43^{\star \star \star}$ & $0.459^{\star \star \star}$ & $0.292^{\star \star \star}$ & $0.476^{\star \star \star}$ & $0.404^{\star \star \star}$ & $0.47^{\star \star \star}$ & $0.242^{\star \star \star}$ & $0.431^{\star \star \star}$ & $0.293^{\star \star \star}$ & $0.361^{\star \star \star}$ & $-0.09^{\star}$ & & & & & \\
\hline 14 WPI: Enjoyment & $0.37^{\star \star \star}$ & $0.339^{\star \star \star}$ & $0.45^{\star \star \star}$ & $0.096^{\star}$ & $0.395^{\star \star \star}$ & $0.508^{\star \star \star}$ & $0.404^{\star \star \star}$ & $0.199^{\star \star \star}$ & $0.145^{\star \star \star}$ & $0.313^{* \star \star}$ & $0.439^{* \star *}$ & 0.013 & $0.374^{\star \star \star}$ & & & & \\
\hline 15 Dospert: Social & $0.325^{\star \star \star}$ & $0.232^{\star \star \star}$ & $0.358^{\star \star \star}$ & $0.146^{\star \star \star}$ & $0.306^{\star \star \star}$ & $0.306^{\star \star \star}$ & $0.34^{\star \star \star}$ & $0.162^{\star \star \star}$ & $0.135^{\star \star}$ & $0.234^{\star \star \star}$ & $0.327^{\star \star \star}$ & 0.025 & $0.327^{\star \star \star}$ & $0.288^{\star \star \star}$ & & & \\
\hline 16 Dospert: Recreational & $0.351^{\star \star \star}$ & $0.146^{\star \star \star}$ & $0.302^{\star \star \star}$ & $0.335^{\star \star \star}$ & $0.326^{\star \star \star}$ & $0.229^{\star \star \star}$ & $0.25^{\star \star \star}$ & $0.196^{\star \star \star}$ & $0.302^{\star \star \star}$ & $0.233^{\star \star \star}$ & $0.124^{\star \star}$ & 0.054 & $0.363^{\star \star \star}$ & $0.184^{\star \star \star}$ & $0.325^{\star \star \star}$ & & \\
\hline 17 PSI: Social Astuteness & $0.445^{\star \star \star}$ & $0.46^{\star \star \star}$ & $0.39^{\star \star \star}$ & $0.174^{\star \star \star}$ & $0.454^{* \star *}$ & $0.518^{\star \star \star}$ & $0.449^{\star \star \star}$ & $0.295^{\star \star \star}$ & $0.185^{\star \star \star}$ & $0.353^{\star \star \star}$ & $0.612^{\star \star \star}$ & $-0.12^{* *}$ & $0.381^{* \star \star}$ & $0.418^{\star \star \star}$ & $0.343^{\star \star \star}$ & $0.214^{\star \star \star}$ & \\
\hline 18 Big 5: Openness & $0.557^{\star \star \star}$ & $0.547^{\star \star \star}$ & $0.563^{\star \star \star}$ & $0.198^{\star \star \star}$ & $0.555^{\star \star \star}$ & $0.49^{\star \star \star}$ & $0.51^{\star \star \star}$ & $0.341^{\star \star \star}$ & $0.341^{\star \star \star}$ & $0.446^{\star \star \star}$ & $0.451^{\star \star \star}$ & 0.061 & $0.452^{\star \star \star}$ & $0.41^{\star \star \star}$ & $0.3^{\star \star \star}$ & $0.198^{\star \star \star}$ & $0.471^{\star \star \star}$ \\
\hline
\end{tabular}

${ }^{*} p<0.05,{ }^{* *} p<0.01,{ }^{* * *} p<0.001$ 
an additional sample $(n=55)$ recruited to increase the sample size $(N=243)$. The retest (post measurement) was done after a period of 30-50 days had elapsed. Correlation analysis indicated adequate temporal stability for each factor: F1 $(r=0.803$; $p<0.001)$, F2 $(r=0.759 ; p<0.001)$, and F3 $(r=0.841$; $p<0.001)$, as well as for the instrument total $(r=0.861$; $p<0.001)$.

\section{Normative Data}

The sample data $(N=551)$ indicate a mean of 53.7 for the total TCPQ and a standard deviation of 12.0. The factors obtained the following values: $\mathrm{F} 1(\mathrm{M}=12.4, \mathrm{SD}=6.37), \mathrm{F} 2(\mathrm{M}=19.4$, $\mathrm{SD}=5.58), \mathrm{F} 3(\mathrm{M}=22, \mathrm{SD}=4.32)$.

\section{DISCUSSION}

The analysis of the psychometric properties of the instrument analyzed indicates both a good fit to the model and acceptable reliability. The salient factors, transgression (F1), challenge (F2) and exploration (F3), correlate moderately and significantly with the scales used, which can be considered as evidence of validity.

The factor named transgression, referring to the violation of norms, maintains a good relationship with the total of the instrument and has the highest explained variance. A metaanalytic work had already reported that creative people question norms (Feist, 1998). This would also imply a probable relationship with intrinsic motivation, in the absence of explicit extrinsic rewards derived from the transgression of norms. This is relatively confirmed by our findings, since the highest F1 correlations are with the Challenge factor of the WPI and the Recreational factor of the Dospert. More recently it has also been pointed out that this norm questioning is part of a group of personality variables that correlate positively with creativity (Feist, 2019). Indeed, creative people may be compelled to violate norms in order to promote change (Bonetto et al., 2021). However, there does not seem to be much evidence in this regard. On an anecdotal level, examples can be pointed out in the case of art. Great creators, for example Picasso, Stravinsky, or Stein broke - transgressed - the canons of their discipline. It is likely that the lack of evidence is due to the fact that transgression is adaptive and not socially harmful. This may yield contradictory data, since rule-breaking is usually posed in an antisocial sense and it is likely that the creative person does not transgress these rules. In this sense, there is evidence indicating that rules also have a positive relationship with creativity (Du et al., 2021), because they can promote positive expectations for creative behavior (Liu Y. et al., 2021).

The challenge factor confirms that willingness to take risks is a variable linked to creativity, as some evidence has reported (Dewett, 2006). F2 may imply that the intellectual stimulation associated with risk taking allows considering alternative perspectives (Liu H. et al., 2021). It could also be explained from an association with the flow state noted by Csikszentmihalyi (2013). This state occurs in a positive relationship between task challenges and task skills (Hamari et al., 2016) and there is evidence about this state being linked to creativity (MacDonald et al., 2006; Dan, 2021). The factor includes items that not only refer to risk-taking but also to one's own perception of recognition and social impact. The creative person willing to challenge may be aware of a socially recognized achievement and the resulting organization of the items indicates this. This would indicate a form of self-efficacy. In fact, it has been reported that when risk willingness is high there is an indirect effect on creativity through creative self-efficacy (Zhang et al., 2015). Furthermore, the correlation of F2 with social astuteness measured with the PSI suggests that social skills may be relevant for taking on challenges related to creative potential.

The desire to know or curiosity is a motivational characteristic and is related to the willingness to explore (Schutte and Malouff, 2020). The items that constitute F3, have this characteristic, and also integrate characteristics of openness and flexibility. Thus, the salient factor supports other findings that point to openness as a preference for exploration and variety, from an empirical point of view (Matz, 2021). Furthermore, the positive correlations between F3, with the openness and BigFive factor and with the intrinsic motivation subscales of the WPI support this notion. On the other hand, the moderate correlation with the "Alternatives" subscale of the CFI confirms the relationship expectations raised in the procedure. At the same time, it indicates the feasibility of establishing cognitive correlates, in this case flexibility, with personality traits such as openness. The above adds to other similar findings (Murdock et al., 2013).

The convergent and discriminant validity analyses yielded some values that may cause concern. F3, showed a value of less than 0.5 in AVE, while in composite reliability it also obtained a value slightly lower than 0.70 . It has been suggested that a value below 0.5 may be acceptable because AVE is a conservative measure (Fornell and Larcker, 1981). Values between 0.6 and 0.7 of CR may also be acceptable when other indicators of model validity are good (Hair et al., 2014), as is the case in the present study. However, the values found question the full validity of the model, despite optimal values in other CFA indices and other reported validity evidence. Therefore, it is suggested that in future studies the number of items in F3 should be increased and it is probably advisable to eliminate item 12 , which has the lowest factor loadings. In our analyses this adjustment did not yield any significant modification, but the inclusion of other items or the replacement of item 12 may have a significant effect.

A finding worth highlighting is that the correlations of the TCPQ-12 with convergent validity measures are similar to the correlations of the K-Docs with the same measures. This, coupled with the correlation between TCPQ-12 and K-Docs, gives greater consistency to the validity evidence found.

\section{Scope and Limitations}

The present study presents some evidence of initial validity, but its relationship with creative potential performance remains to be empirically determined. Since one of the most commonly used measures to evaluate creative potential is divergent thinking, it is suggested that this relationship be analyzed in future studies. For example, correlational studies can be done with the CREA (Corbalá-Berná et al., 2016), or with the Torrance Tests of Creative Thinking (Torrance and Presbury, 1984). This will make it possible to 
address the predictive validity of the TCPQ-12 in greater depth. For this purpose, it is also suggested to conduct studies in which, sometime after applying the TCPQ-12, the participant's creative performance in specific tasks or domains is evaluated. The present research was done during the COVID-19 pandemic, which prevented and still prevents us from assessing the participants directly as the convergent thinking tests mentioned above would demand. It is also important to note that the present instrument is not intended to assess a creative way of acting or creative characteristics, as could be done with the $\mathrm{rCAB}$ (Runco, 2011) but traits that are associated with creative potential. In addition, examining the invariance of the instrument would help to better determine its scope and limitations. Finally, F1 was developed as a form of adaptive or positive transgression. For this reason we did not propose to study its relationship with any explicit measure of transgression, as they are typically associated with antisocial behavior. However, perhaps future studies could address this, especially for malevolent creativity (Hao et al., 2016).

\section{Conclusion}

In addition to achieving a concise instrument with adequate psychometric properties for a first version of the inventory, the present study provides empirical evidence on individual traits and dispositions related to creative potential. Presenting three of these dispositions as a model that contributes to explaining part of the creative potential is a novel proposal. Exploration orientation, flexible, self-motivated, willing to take on challenges and to positively transgress social norms seem to be relevant to creative potential. The items that make up the salient factors allow us to make the above point. The TCPQ-12 seeks to evaluate only some traits in an integrated way, but looking for a translational

\section{REFERENCES}

Amabile, T. M., and Pratt, M. G. (2016). The dynamic componential model of creativity and innovation in organizations: making progress, making meaning. Res. Organ. Behav. 36, 157-183. doi: 10.1016/j.riob.2016.10.001

Amabile, T. M., Hill, K. G., Hennessey, B. A., and Tighe, E. M. (1994). The work preference inventory: assessing intrinsic and extrinsic motivational orientations. J. Pers. Soc. Psychol. 66, 950-967. doi: 10.1037/0022-3514.66.5.950

Aydintan, B., Göksel, A., and Ekmekçioğlu, E. B. (2014). Politik yeteneğin öğrenci ve çalışanların girişimcilik niyeti üzerindeki mediatör ( $\operatorname{arac1}$ ) etkisi: görgül bir çalışma/Mediator effect of political ability on entrepreneurial intention of students and employees: an empirical study. Acad. Rev. Econ. Adm. Sci. 7, 95-112.

Baas, M., De Dreu, C. K., and Nijstad, B. A. (2008). A meta-analysis of 25 years of mood-creativity research: hedonic tone, activation, or regulatory focus? Psychol. Bull. 134, 779-806. doi: 10.1037/a0012815

Baas, M., De Dreu, C. K., and Nijstad, B. A. (2011). When prevention promotes creativity: the role of mood, regulatory focus, and regulatory closure. J. Pers. Soc. Psychol. 100, 794-809.

Barrett, P. (2007). Structural equation modelling: adjudging model fit. Pers. Individ. Dif. 42, 815-824. doi: 10.1016/j.paid.2006.09.018

Batey, M., Furnham, A., and Safiullina, X. (2010). Intelligence, general knowledge and personality as predictors of creativity. Learn. Individ. Dif. 20, 532-535. doi: 10.1016/j.lindif.2010.04.008 sense. For example, the TCPQ-12 can be used in organizational settings as a possible predictor of creative potential at work.

Finally, like any psychological variable, creativity happens in a multifactorial context. Predicting creative potential is a challenge with a long way to go. Several variables mediate this process, for example affective or emotional variables (Baas et al., 2008; Ivcevic and Brackett, 2015), cognitive (Benedek et al., 2014), and of course environmental characteristics (Chi et al., 2020), to name a few. However, having forms of measurement such as the one presented here help to address this challenge.

\section{DATA AVAILABILITY STATEMENT}

The datasets presented in this article are not readily available due to protection of participant privacy. Requests to access the datasets should be directed to JP-C, julioc.penagos@udlap.mx.

\section{ETHICS STATEMENT}

The studies involving human participants were reviewed and approved by Ethics Committee at Universidad de las Américas Puebla. The patients/participants provided their written informed consent to participate in this study.

\section{AUTHOR CONTRIBUTIONS}

Both authors contributed, to varying degrees, in each of the following: conception of the study, methodology and formal analysis, writing of the manuscript, review of form and content, and approval of the final version of the manuscript. JP-C was in charge of the project administration and supervision.

Benedek, M., Jauk, E., Sommer, M., Arendasy, M., and Neubauer, A. C. (2014). Intelligence, creativity, and cognitive control: the common and differential involvement of executive functions in intelligence and creativity. Intelligence 46, 73-83. doi: 10.1016/j.intell.2014.05.007

Benet-Martínez, V., and John, O. P. (1998). Los Cinco Grandes across cultures and ethnic groups: multitrait-multimethod analyses of the big five in Spanish and English. J. Pers. Soc. Psychol. 75, 729-750. doi: 10.1037/0022-3514.75.3.729

Blais, A.-R., and Weber, E. U. (2006). A domain-specific risk-taking (DOSPERT) scale for adult populations. Judgm. Decis. Mak. 1, 33-47.

Boateng, G. O., Neilands, T. B., Frongillo, E. A., Melgar-Quiñonez, H. R., and Young, S. L. (2018). Best practices for developing and validating scales for health, social, and behavioral research: a primer. Front. Public Health 6:149. doi: 10.3389/fpubh.2018.00149

Bonetto, E., Pichot, N., Pavani, J.-B., and Adam-Troïan, J. (2021). The paradox of creativity. New Ideas Psychol. 60:100820. doi: 10.1016/j.newideapsych.2020. 100820

Chang, Y.-Y., and Chen, M.-H. (2020). Creative entrepreneurs' creativity, opportunity recognition, and career success: is resource availability a doubleedged sword? Eur. Manage. J. 38, 750-762. doi: 10.1016/j.emj.2020.03.004

Chang, Y.-Y., and Shih, H.-Y. (2019). Work curiosity: a new lens for understanding employee creativity. Hum. Resour. Manage. Rev. 29:100672.

Chi, N., Liao, H., and Chien, W. (2020). Having a creative day: a daily diary study of the interplay between daily activating moods and physical work environment on daily creativity. J. Creat. Behav. 1-7. doi: 10.1002/jocb.488 
Corazza, G. E. (2016). Potential originality and effectiveness: the dynamic definition of creativity. Creat. Res. J. 28, 258-267. doi: 10.1080/10400419.2016. 1195627

Corbalá-Berná, J., Martiìnez-Zaragoza, F., Donolo, D. S., Alonso-Monreal, C., Tejerina-Arreal, M., and Liminpana-Gras, R. M. (2016). CREA. Inteli-Gencia Creativa [CREA. Creative Intelligence]. Madrid: TEA Ediciones.

Csikszentmihalyi, M. (2013). Creativity: Flow and the Psychology of Discovery and Invention. New York, NY: Harper Perennial.

Dan, Y. (2021). Examining the relationships between learning interest, flow, and creativity. Sch. Psychol. Int. 42, 157-169. doi: 10.1177/0143034320983399

de Jesus, S., Rus, C., Lens, W., and Imaginário, S. (2013). Intrinsic motivation and creativity related to product: a meta-analysis of the studies published between 1990-2010. Creat. Res. J. 25, 80-84. doi: 10.1080/10400419.2013.752235

Dennis, J. P., and Vander Wal, J. S. (2010). The cognitive flexibility inventory: instrument development and estimates of reliability and validity. Cogn. Ther. Res. 34, 241-253. doi: 10.1007/s10608-009-9276-4

Deshayes, C., Paban, V., Ferrer, M.-H., Alescio-Lautier, B., and Chambon, C. (2021). A comprehensive approach to study the resting-state brain network related to creative potential. Brain Struct. Funct. 226, 1743-1753. doi: 10.1007/ s00429-021-02286-9

Dewett, T. (2006). Exploring the role of risk in employee creativity. J. Creat. Behav. $40,27-45$.

Dewett, T. (2007). Linking intrinsic motivation, risk taking, and employee creativity in an R\&D environment. R\&D Manage. 37, 197-208. doi: 10.1111/ j.1467-9310.2007.00469.x

Diedrich, J., Benedek, M., Jauk, E., and Neubauer, A. C. (2015). Are creative ideas novel and useful? Psychol. Aesthet. Creat. Arts 9, 35-40. doi: 10.1037/a0038688

Du, X., Zhang, H., Zhang, S., Zhang, A., and Chen, B. (2021). Creativity and leadership in the creative industry: a study from the perspective of social norms. Front. Psychol. 12:651817. doi: 10.3389/fpsyg.2021.651817

Epstein, R., and Phan, V. (2012). Which competencies are most important for creative expression? Creat. Res. J. 24, 278-282. doi: 10.1080/10400419.2012. 726579

Evans, N. S., Todaro, R. D., Schlesinger, M. A., Golinkoff, R. M., and HirshPasek, K. (2021). Examining the impact of children's exploration behaviors on creativity. J. Exp. Child Psychol. 207:105091. doi: 10.1016/j.jecp.2021.105091

Eysenck, H. J. (1993). Creativity and personality: suggestions for a theory. Psychol. Inq. 4, 147-178. doi: 10.1207/s15327965pli0403_1

Eysenck, H. J. (1994). "The measurement of creativity," in The Dimensions of Creativity, ed. M. Boden (Cambridge, MA: The MIT Press), 199-242.

Feist, G. J. (1998). A meta-analysis of personality in scientific and artistic creativity. Pers. Soc. Psychol. Rev. 2, 290-309. doi: 10.1207/s15327957pspr0204_5

Feist, G. J. (2019). Creativity and the big two model of personality: plasticity and stability. Curr. Opin. Behav. Sci. 27, 31-35.

Ferris, G. R., Treadway, D. C., Kolodinsky, R. W., Hochwarter, W. A., Kacmar, C. J., Douglas, C., et al. (2005). Development and validation of the political skill inventory. J. Manage. 31, 126-152. doi: 10.1037/t03663-000

Fornell, C., and Larcker, D. F. (1981). Evaluating structural equation models with unobservable variables and measurement error. J. Market. Res. 18, 39-50. doi: $10.1177 / 002224378101800104$

Freiberg-Hoffmann, A., Vigh, C., and Fernández-Liporace, M. (2019). Creative personality scale. A new version for college students from Argentina. Anal. Psicol. 35, 290-299. doi: 10.6018/analesps.35.2.346131

Friedman, R. S., and Förster, J. (2001). The effects of promotion and prevention cues on creativity. J. Pers. Soc. Psychol. 81, 1001-1013. doi: 10.1037/0022-3514. 81.6.1001

Furnham, A., Batey, M., Anand, K., and Manfield, J. (2008). Personality, hypomania, intelligence and creativity. Pers. Individ. Dif. 44, 1060-1069. doi: 10.1016/j.paid.2007.10.035

Fürst, G., Ghisletta, P., and Lubart, T. (2016). Toward an integrative model of creativity and personality: theoretical suggestions and preliminary empirical testing. J. Creat. Behav. 50, 87-108. doi: 10.1002/jocb.71

George, J. M., and Zhou, J. (2001). When openness to experience and conscientiousness are related to creative behavior: an interactional approach. J. Appl. Psychol. 86, 513-524. doi: 10.1037/0021-9010.86.3.513

Glover, J. A., and Sautter, F. (1977). Relation of four components of creativity to risk-taking preferences. Psychol. Rep. 41, 227-230. doi: 10.2466/pr0.1977.41.1. 227
Gough, H. G. (1979). A creative personality scale for the adjective check list. J. Pers. Soc. Psychol. 37, 1398-1405. doi: 10.1037/0022-3514.37.8.1398

Gough, H. G., and Heilbrun, A. B. (1965/1983). The Adjective Check List Manual. Palo Alto, CA: Consulting Psychologists Press.

Grigorescu, D. (2020). Curiosity, intrinsic motivation and the pleasure of knowledge. J. Educ. Sci. Psychol. 10, 16-23.

Guilford, J. P. (1950). Creativity. Am. Psychol. 5, 444-454. doi: 10.1037/h0063487

Guo, J., Zhang, J., De Fruyt, F., and Pang, W. (2021). The bright and dark personality correlates of creative potentials, creative activities, and creative achievements. Curr. Psychol. doi: 10.1007/s12144-021-01710-x

Hagtvedt, L. P., Dossinger, K., Harrison, S. H., and Huang, L. (2019). Curiosity made the cat more creative: specific curiosity as a driver of creativity. Organ. Behav. Hum. Decis. Process. 150, 1-13. doi: 10.1016/j.obhdp.2018.1 0.007

Hahn, M. H., Choi, D. Y., and Lee, K. C. (2011). "Effects of social and emotional intelligence on the creative process and individual creativity," in $U$ - and E-Service, Science and Technology. UNESST 2011. Communications in Computer and Information Science, Vol. 264, eds T.-H. Kim, H. Adeli, J. Ma, W.-C. Fang, B.-H. Kang, B. Park, et al. (Berlin: Springer), 217-226. doi: 10.1007/978-3-64227210-3_26

Hair, J. F., Black, B. J., and Anderson, R. E. (2014). Multivariate Data Analysis. London: Person Education Limited.

Hamari, J., Shernoff, D. J., Rowe, E., Coller, B., Asbell-Clarke, J., and Edwards, T. (2016). Challenging games help students learn: an empirical study on engagement, flow and immersion in game-based learning. Comput. Hum. Behav. 54, 170-179. doi: 10.1037/t46666-000

Hamilton, D. (2019). Developing and testing inhibitors of curiosity in the workplace with the curiosity code index (CCI). Heliyon 5:e01185. doi: 10.1016/ j.heliyon.2019.e01185

Hao, N., Tang, M., Yang, J., Wang, Q., and Runco, M. A. (2016). A new tool to measure malevolent creativity: the malevolent creativity behavior scale. Front. Psychol. 7:682. doi: 10.3389/fpsyg.2016.00682

Highhouse, S., Nye, C. D., Zhang, D. C., and Rada, T. B. (2017). Structure of the dospert: Is there evidence for a general risk factor? J. Behav. Decis. Mak. 30, 400-406. doi: 10.1002/bdm.1953

Horn, J. L. (1965). A rationale and test for the number of factors in factor analysis. Psychometrika 30, 179-185. doi: 10.1007/BF02289447

Hornberg, J., and Reiter-Palmon, R. (2017). "Creativity and the big five personality traits: is the relationship dependent on the creativity measure?", in Cambridge Handbooks in Psychology. The Cambridge Handbook of Creativity and Personality Research, eds G. J. Feist, R. Reiter-Palmon, and J. C. Kaufman (Cambridge: Cambridge University Press), 275-293. doi: 10.1017/ 9781316228036.015

Hu, L. T., and Bentler, P. M. (1999). Cutoff criteria for fit indexes in covariance structure analysis: conventional criteria versus new alternatives. Struct. Equ. Modeling 6, 1-55.

Ivcevic, Z., and Brackett, M. A. (2015). Predicting creativity: interactive effects of openness to experience and emotion regulation ability. Psychol. Aesthet. Creat. Arts 9, 480-487. doi: 10.1037/a0039826

Jach, H. K., and Smillie, L. D. (2021). Testing the information-seeking theory of openness/intellect. Eur. J. Pers. 35, 103-119. doi: 10.1002/per. 2271

Jirout, J., and Klahr, D. (2012). Children's scientific curiosity: in search of an operational definition of an elusive concept. Dev. Rev. 32, 125-160. doi: 10 . 1016/j.dr.2012.04.002

Kaiser, H. F. (1960). The application of electronic computers to factor analysis Educ. Educ. Psychol. Meas. 20, 141-151. doi: 10.1177/001316446002000116

Kaufman, J. C. (2012). Counting the muses: development of the Kaufman domains of creativity scale (K-DOCS). Psychol. Aesthet. Creat. Arts 6, 298-308. doi: $10.1037 / \mathrm{a} 0029751$

Lawshe, C. H. (1975). A quantitative approach to content validity. Pers. Psychol. 28, 563-575. doi: 10.1111/j.1744-6570.1975.tb01393.x

Lee, J.-E., Day, J. D., Meara, N. M., and Maxwell, S. (2002). Discrimination of social knowledge and its flexible application from creativity: a multitrait-multimethod approach. Pers. Individ. Dif. 32, 913-928. doi: 10.1016/S0191-8869(01)0 0099-X

Liu, D., Jiang, K., Shalley, C. E., Keem, S., and Zhou, J. (2016). Motivational mechanisms of employee creativity: a meta-analytic examination and 
theoretical extension of the creativity literature. Organ. Behav. Hum. Decis. Process. 137, 236-263. doi: 10.1016/j.obhdp.2016.08.001

Liu, H., Dust, S. B., Xu, M., and Ji, Y. (2021). Leader-follower risk orientation incongruence, intellectual stimulation, and creativity: a configurational approach. Pers. Psychol. 74, 143-173. doi: 10.1111/peps.12417

Liu, Y., Vriend, T., and Janssen, O. (2021). To be (Creative), or not to be (Creative)? A sensemaking perspective to creative role expectations. J. Bus. Psychol. 36, 139-153. doi: 10.1007/s10869-019-09669-0

Luescher, R., Barthelmess, P. Y., Kim, S., Richter, U. H., and Mittag, M. (2019). Conceptualizing creativity: general and cultural biases in Gough's creative personality scale. J. Creat. Behav. 53, 30-43. doi: 10.1002/jocb.160

MacDonald, R., Byrne, C., and Carlton, L. (2006). Creativity and flow in musical composition: an empirical investigation. Psychol. Music 34, 292-306. doi: 10. 1177/0305735606064838

MacKinnon, D. W. (1963). "Creativity and images of the self," in The Study of Lives, ed. R. W. White (New York, NY: Atherton Press), 252-278.

MacKinnon, D. W. (1975/2017). "IPAR's contribution to the conceptualization and study of creativity," in Perspectives in Creativity, eds I. A. Taylor and J. W. Getzels (Abingdon-on-Thames: Routledge), 60-89. doi: 10.4324/ 9781315126265

Marsh, H. W., and Grayson, D. (1995). "Latent variable models of multitraitmultimethod data," in Structural Equation Modeling: Concepts, Issues and Applications, ed. R. Hoyle (Thousand Oaks, CA: Sage Publications), 177-198.

Matz, S. C. (2021). Personal echo chambers: openness-to-experience is linked to higher levels of psychological interest diversity in large-scale behavioral data. J. Pers. Soc. Psychol. 1-17. doi: 10.1037/pspp0000324

McCrae, R. R., and Costa, P. T. (2008). "The five-factor theory of personality," in Handbook of Personality Theory and Research, eds P. Olive, R. W. Robins, and L. A. Pervin (New York, NY: The Guilford Press), 159-181.

Mielniczuk, E., and Laguna, M. (2020). Positive affect mediates the relationship between self-efficacy and innovative behavior in entrepreneurs. J. Creat. Behav. 54, 267-278. doi: 10.1002/jocb.364

Milicevic, A., Woolfe, S., Blazely, A., Lenroot, R., and Sewell, S. (2020). Enhancing creativity through seven stages of transformation in a graduate level writing course-a mixed method study. Think. Skills Creat. 38:100712. doi: 10.1016/j. tsc.2020.100712

Møller, S. J. (2015). Imagination, playfulness, and creativity in children's play with different toys. Am. J. Play 7, 322-346.

Mu, Y., Kitayama, S., Han, S., and Gelfand, M. J. (2015). How culture gets embrained: cultural differences in event-related potentials of social norm violations. Proc. Natl. Acad. Sci. U.S.A. 112, 15348-15353. doi: 10.1073/pnas. 1509839112

Mumford, M. D., and Gustafson, S. B. (1988). Creativity syndrome: integration, application, and innovation. Psychol. Bull. 103, 27-43. doi: 10.1037/0033-2909. 103.1.27

Murdock, K. W., Oddi, K. B., and Bridgett, D. J. (2013). Cognitive correlates of personality: links between executive functioning and the big five personality traits. J. Individ. Dif. 34, 97-104. doi: 10.1027/1614-0001/a000104

Penagos-Corzo, J. C. (2018). Psicobiología de la creatividad, emociones y actitud creativa/ psychobiology of creativity, emotions and creative attitude. Rev. Int. Educ. Justicia Soc. 7, 33-46. doi: 10.15366/riejs2018.7.2.002

Penagos-Corzo, J. C., Antonio, A. A., Dorantes-Argandar, G., and Alcázar-Olán, R. J. (2019). Psychometric properties and development of a scale designed to evaluate the potential of predatory violent behavior. Front. Psychol. 10:1648. doi: 10.3389/fpsyg.2019.01648

Penagos-Corzo, J. C., Esquivel, M. E. O., and Cucarella, M. S. P. (2017). Propiedades psicométricas del work preference inventory (WPI) en una muestras de adultos jóvenes mexicanos/ psychometric properties of the work preference inventory (WPI) in a sample of young Mexican adults. Univ. Psychol. 16, 1-15. doi: 10.11144/Javeriana.upsy16-2.ppwp

Prabhu, V., Sutton, C., and Sauser, W. (2008). Creativity and certain personality traits: understanding the mediating effect of intrinsic motivation. Creat. Res. J. 20, 53-66. doi: 10.1080/10400410701841955

Romo, M. (2019). Psicologiia de la Creatividad. Perspectivas Contemporaineas [Psychology of Creativity. Contemporary perspectives]. Milano: Paidos.

Runco, M. A. (2011). Creativity Testing: Manual for the Runco Creativity Assessment Battery. Bishop, GA: Creativity Testing Service.
Runco, M. A., and Jaeger, G. J. (2012). The standard definition of creativity. Creat. Res. J. 24, 92-96. doi: 10.1080/10400419.2012.650092

Sampedro, A., and Peña, J. (2019). Executive functions mediate the association between bilingualism and creativity in preadolescents. Think. Skills Creat. 34:100605. doi: $10.1016 /$ j.tsc.2019.100605

Sawyer, K. (2011). The cognitive neuroscience of creativity: a critical review. Creat. Res. J. 23, 137-154. doi: 10.1080/10400419.2011.571191

Sawyer, R. K. (2012). Explaining Creativity: The Science of Human Innovation, 2nd Edn. Oxford: Oxford University Press.

Schermelleh-Engel, K., Moosbrugger, H., and Müller, H. (2003). Evaluating the fit of structural equation models: tests of significance and descriptive goodness-offit measures. Methods Psychol. Res. 8, 23-74.

Schuldberg, D. (1990). Schizotypal and hypomanic traits, creativity, and psychological health. Creat. Res. J. 3, 218-230. doi: 10.1080/ 10400419009534354

Schutte, N. S., and Malouff, J. M. (2020). Connections between curiosity, flow and creativity. Pers. Individ. Dif. 152:109555. doi: 10.1016/j.paid.2019.109555

Sternberg, R. J., and Lubart, T. I. (2002). Defying the Crowd: Cultivating Creativity in a Culture of Conformity. New York, NY: Free Press.

Taylor, C. L., and Kaufman, J. C. (2021). The creative trait motivation scales. Think. Skills Creat. 39:100763. doi: 10.1016/j.tsc.2020.100763

Torrance, E. P., and Presbury, J. (1984). The criteria of success used in 242 recent experimental studies of creativity. Creat. Child Adult Q. 9, 238-243.

Tristaìn-López, A. (2008). Modificacioìn al modelo de lawshe para el dictamen cuantitativo de la validez de contenido de un instrumento objetivo/modification of Lawshe's model for quantitative judgement of the content validity of an objective instrument. Av. Med. 6, 37-48.

Tsai, K. H., and Zheng, L. L. (2021). Bridging employee curiosity and service creativity: a new lens. J. Serv. Theory Pract. 31, 821-844. doi: 10.1108/JSTP-112020-0262

Tyagi, V., Hanoch, Y., Hall, S. D., Runco, M., and Denham, S. L. (2017). The risky side of creativity: domain specific risk taking in creative individuals. Front. Psychol. 8:145. doi: 10.3389/fpsyg.2017.00145

World Medical Association (2013). Declaration of Helsinki. Ethical Principles for Medical Research Involving Human Subjects. Ferney-Voltaire: World Medical Association.

Xia, Y., Zhuang, K., Sun, J., Chen, Q., Wei, D., Yang, W., et al. (2017). Emotion-related brain structures associated with trait creativity in middle children. Neurosci. Lett. 658, 182-188. doi: 10.1016/j.neulet.2017.0 8.008

Zamorano, E. R., Carrillo, C. Á, Silva, A. P., Sandoval, A. M., and Pastrana, I. M. R. (2014). Psychometric properties of the big five inventory in a Mexican sample. Salud Mental 37, 491-497. doi: 10.17711/SM.0185-3325.201 4.059

Zhang, Y., Long, L., and Zhang, J. (2015). Pay for performance and employee creativity: the importance of procedural justice and willingness to take risks. Manage. Decis. 53, 1378-1397. doi: 10.1108/MD-11-2013-0596

Zhou, K. (2021). The influence of creative personality and goal orientation on innovation performance. Front. Psychol. 12:634951. doi: 10.3389/fpsyg.2021. 740450

Conflict of Interest: The authors declare that the research was conducted in the absence of any commercial or financial relationships that could be construed as a potential conflict of interest.

Publisher's Note: All claims expressed in this article are solely those of the authors and do not necessarily represent those of their affiliated organizations, or those of the publisher, the editors and the reviewers. Any product that may be evaluated in this article, or claim that may be made by its manufacturer, is not guaranteed or endorsed by the publisher.

Copyright () 2021 Penagos-Corzo and Saucedo. This is an open-access article distributed under the terms of the Creative Commons Attribution License (CC BY). The use, distribution or reproduction in other forums is permitted, provided the original author(s) and the copyright owner(s) are credited and that the original publication in this journal is cited, in accordance with accepted academic practice. No use, distribution or reproduction is permitted which does not comply with these terms. 